\title{
Investigation of europium concentration dependence on the luminescent properties of borogermanate glasses
}

\author{
Melis Gökçe $^{a, *}$, Ufuk Şentürk ${ }^{b}$, Deniz K. Uslu ${ }^{a}$, Gözde Burgaz ${ }^{a}$, Yüksel Şahin ${ }^{c}$, \\ Aytaç Gürhan Gökçe ${ }^{\mathrm{d}}$ \\ a Department of Physics, Adnan Menderes University, Aydin 09010, Turkey \\ b Department of Materials Science and Engineering, Izmir Institute of Technology, İzmir 35430, Turkey \\ c Department of Chemistry, Adnan Menderes University, Aydin 09010, Turkey \\ d Department of Physics, Dokuz Eylül University, İzmir 35160, Turkey
}

\section{A R T I C L E I N F O}

\section{Keywords:}

Borogermanate glass

Europium

Luminescence

Judd-Ofelt

Decay time

\begin{abstract}
A B S T R A C T
In order to elucidate the effect of europium content on the optical and luminescent properties of borogermanate glasses, a series of $\mathrm{Eu}^{3+}$ doped $30 \mathrm{~B}_{2} \mathrm{O}_{3}-40 \mathrm{GeO}_{2}-(30-\mathrm{x}) \mathrm{Gd}_{2} \mathrm{O}_{3}$ glasses with various doping levels $(\mathrm{x}=1-9 \mathrm{~mol} \%)$ have been synthesized and studied with transmission, absorption, photoluminescence and decay time measurements. The transmission spectra proved that the title glasses maintained a high transparency about $80 \%$ in the 440 to $900 \mathrm{~nm}$ region. Based on the absorption spectra, the optical band gaps obtained from Tauc's plot can be narrowed by increasing content of $\mathrm{Eu}^{3+}$. From the photoluminescence spectra, the strongest red emission has been observed from the ${ }^{5} \mathrm{D}_{0} \rightarrow{ }^{7} \mathrm{~F}_{2}$ level of $\mathrm{Eu}^{3+}$ ions in borogermanate glasses. The strongest emission and excitation intensities of $\mathrm{Eu}^{3+}$ ions are at the doping level of $\mathrm{x}=7 \mathrm{~mol} \%$ and then these intensities decrease due to concentration quenching. The red to orange ratio (R/O) of ${ }^{5} \mathrm{D}_{0} \rightarrow{ }^{7} \mathrm{~F}_{2}$ to ${ }^{5} \mathrm{D}_{0} \rightarrow{ }^{7} \mathrm{~F}_{1}$ transitions has been investigated to predict the local environment of $\mathrm{Eu}^{3+}$ ions. Judd-Ofelt ( J-O) analyses have been performed from the emission spectra. The values of R/O and $\Omega_{2}$ present an increase with increasing doping level, indicating the lower symmetric environment for $\mathrm{Eu}^{3+}$ ions and higher covalency for Eu-O bond. The emission efficiency calculated from $\mathrm{J}-\mathrm{O}$ theory is $75 \%$ at $\mathrm{x}=2 \mathrm{~mol} \%$. The decay time curves of ${ }^{6} \mathrm{P}_{7 / 2} \rightarrow{ }^{8} \mathrm{~S}_{7 / 2}$ transition of $\mathrm{Gd}^{3+}$ ions and ${ }^{5} \mathrm{D}_{0}-{ }^{7} \mathrm{~F}_{2}$ transition of $\mathrm{Eu}^{3+}$ ions confirm the energy transfer from $\mathrm{Gd}^{3+}$ to $\mathrm{Eu}^{3+}$ ions.
\end{abstract}

\section{Introduction}

Due to their unique optical properties, rare earth (RE) doped glasses are very attractive materials for diverse optical devices, such as advanced laser materials, plasma displays, optical waveguides, fiber amplifiers, efficient upconverters [1-4]. For the highest performance for these devices the optical properties of RE ions must be correlated with their local environment in detail [5]. In order to develop new optical devices borate, silicate and phosphate glass systems have been studied as host materials for the incorporation of trivalent RE ions [6]. In view of their high RE ion solution capacity, high thermal stability, high transparency, lower melting point, lower phonon energy, ease of shaping and low cost properties, borogermanate glasses surpass phosphate, silicate or borosilicate glass systems [7-9]. Borogermanate glasses have been used in several application areas that include scintillators, solar cells, solid state lasers and glass fibers [10-13]. Within other RE elements, $\mathrm{Eu}^{3+}$ ions are very effective in the investigation of the local environment of the glass materials, owing to its relatively simple energy level and hypersensitive ${ }^{7} \mathrm{~F}_{0} \rightarrow{ }^{5} \mathrm{D}_{2}$ transition [5,14]. Because of the properties stated above research have been conducted on $\mathrm{Eu}^{3+}$ doped borogermanate systems [15-17].

Glass systems doped with $\mathrm{Gd}^{3+}$ have been studied for various applications such as medical therapy [18], scintillator [19] and x-ray imaging [20]. In addition $\mathrm{Gd}^{3+}$ ion has been studied due to its significant importance in the efficient energy transfer to the incorporated ions (such as $\mathrm{Eu}^{3+}$ ) [20-25]. Luminescent properties of glasses can be improved by energy transfer between these ions $[20,26,27]$.

In the present work a series of europium-gadolinium co-doped borogernanate glasses have been designed for use as glass scintillators. The structural analyses of these glasses have been determined by x-ray diffraction (XRD) and Fourier transform infrared (FTIR) measurements. Absorption, transmittance, photoluminescence (PL) spectra, Judd-Ofelt analysis and decay time measurements have been evaluated in order to obtain optical and luminescent properties of borogermanate glasses as a function of $\mathrm{Eu}^{3+}$ concentration.

\footnotetext{
* Corresponding author.

E-mail address: mgokce@adu.edu.tr (M. Gökçe).
} 


\section{Experimental methods}

The glasses with composition of $30 \mathrm{~B}_{2} \mathrm{O}_{3}-40 \mathrm{GeO}_{2}-(30-\mathrm{x}) \mathrm{Gd}_{2} \mathrm{O}_{3}$ $\mathrm{xEu}_{2} \mathrm{O}_{3}(\mathrm{x}=1,2,3,5,7,9 \mathrm{~mol} \%$; labeled as $\mathrm{BGGEx})$ have been prepared by melt quenching method. The raw materials used for the prepared glasses were $\mathrm{H}_{3} \mathrm{BO}_{3}$ (99.99\%, Alfa Aesar), $\mathrm{GeO}_{2}$ (>99.99\%, Aldrich), $\mathrm{Gd}_{2} \mathrm{O}_{3}$ (99.9\%, Aldrich) and $\mathrm{Eu}_{2} \mathrm{O}_{3}$ (99.9\%, Aldrich). About $10 \mathrm{~g}$ batches were mixed by grinding homogeneously in an agate mortar and melted in an alumina crucible under air atmosphere at $1300 \sim 1400{ }^{\circ} \mathrm{C}$ for $3 \mathrm{~h}$. The melt was poured onto a preheated stainless steel plate and pressed by another plate and then annealed at $550-600{ }^{\circ} \mathrm{C}$ for $6 \mathrm{~h}$ to release internal stresses and avoid cracking of the sample. Optical measurements were done on the polished glass samples with a thickness about $2.5 \mathrm{~mm}$. XRD measurements were carried out using Rigaku-Rint 2200/PC (Ultima 3) diffractometer in the range of $10^{\circ}$ and $90^{\circ}$. The FTIR spectrum was recorded using Perkin-Elmer BX-II FTIR spectrometer in the range of $400-4000 \mathrm{~cm}^{-1}$. The glass densities were determined according to the Archimedes principle by using distilled water as an immersion liquid. Absorption and transmittance spectra were measured on a Perkin-Elmer Lambda $25 \mathrm{UV}$-vis spectrometer. The photoluminescence excitation and emission spectra were recorded by FluoroMax-4 (Horiba Jobin Yvon) spectrofluorometer equipped with a $150 \mathrm{~W}$ xenon lamp source. The decay time measurements were carried out using a Time Correlated Single Photon Counting (TCSPC) system (Edinburgh Instruments) with a micro second flash lamp as an excitation source. All the measurements were carried out at room temperature.

\section{Results and discussion}

Various physical properties including molecular weight (M), density $(\rho)$, refractive index $(n)$, molar volume $\left(V_{m}\right)$, packing density $(P D)$, rare earth-ion concentration $(N)$, polaron radius $\left(r_{p}\right)$ and critical distance $\left(\mathrm{R}_{\mathrm{c}}\right)$ for $\mathrm{Eu}^{3+}$ doped borogermanate glasses have been provided in Table 1. The refractive indexes of glasses have been calculated using Gladstone-Dale relation [28]. The critical distances $\left(R_{c}\right)$ and other calculated physical properties of glasses have been obtained according to literature $[29,30]$, respectively.

As the molecular mass of $\mathrm{Eu}^{3+}$ ion is less than $\mathrm{Gd}^{3+}$ ion, the glass density decreases gradually by the increase in content of $\mathrm{Eu}^{3+}$ ions. The critical distance between $\mathrm{Eu}^{3+}$ ions is higher than the polaron radius for all samples. Both the values of $R_{c}$ and $r_{p}$ reduce with the increase of $\mathrm{Eu}^{3+}$ ion content [22]).

\subsection{Structural analysis}

The XRD pattern of $\mathrm{x}=1 \mathrm{~mol} \% \mathrm{Eu}^{3+}$ doped borogermanate glass is

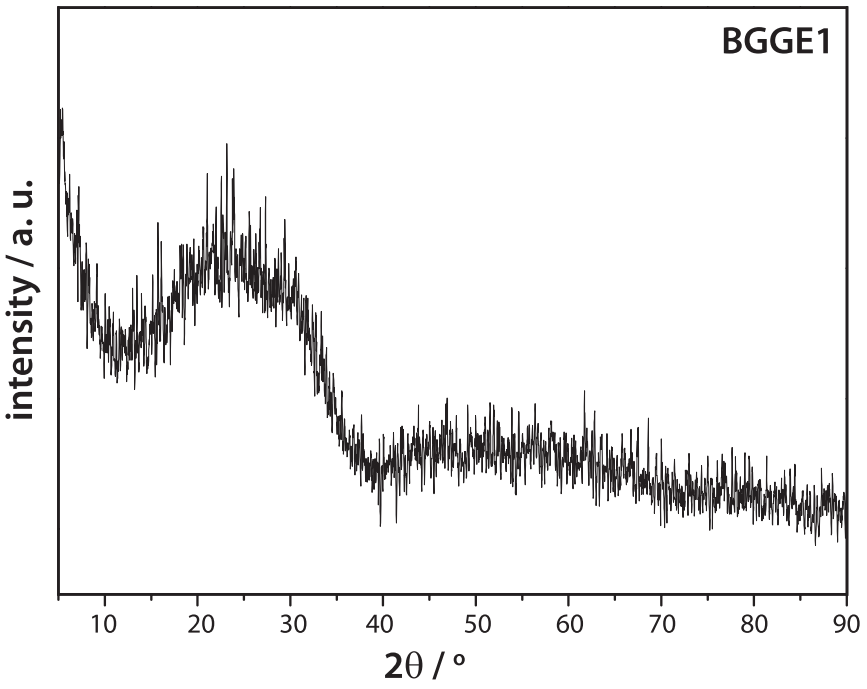

Fig. 1. XRD pattern of BGGE1 glass.

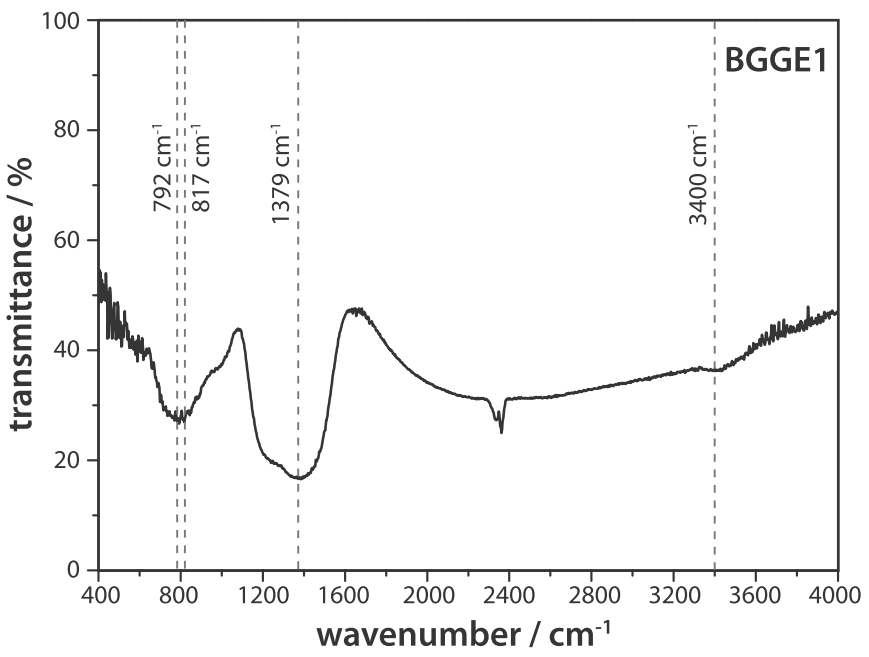

Fig. 2. Infrared transmission spectrum of BGGE1 glass.

shown in Fig. 1. The spectrum exhibits a broad scattering at around $25^{\circ}$ and $55^{\circ}$ and lacks the presence of specific crystalline peaks, indicating the amorphous nature of network structure.

As a representative case, the IR spectra of BGGE1 glass (Fig. 2) has been evaluated to identify the structural formation. The typical absorption band of $\mathrm{OH}^{-}$group is centered at $3400 \mathrm{~cm}^{-1}$, which reveals

Table 1

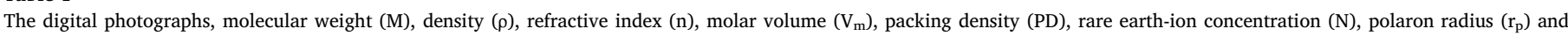
critical distance $\left(\mathrm{R}_{\mathrm{c}}\right)$.

\begin{tabular}{|c|c|c|c|c|c|c|}
\hline & BGGE1 & BGGE2 & BGGE3 & BGGE5 & BGGE7 & BGGE9 \\
\hline $\mathrm{M}(\mathrm{g} / \mathrm{mol})$ & 171.585 & 171.279 & 171.173 & 170.962 & 170.751 & 170.539 \\
\hline$\rho\left(\mathrm{g} / \mathrm{cm}^{3}\right)$ & 4.807 & 4.824 & 4.818 & 4.764 & 4.778 & 4.732 \\
\hline $\mathrm{n}$ & 1.700 & 1.702 & 1.701 & 1.693 & 1.695 & 1.689 \\
\hline $\mathrm{V}_{\mathrm{M}}\left(\mathrm{cm}^{3} / \mathrm{mol}\right)$ & 35.694 & 35.505 & 35.527 & 35.886 & 35.736 & 36.039 \\
\hline $\mathrm{PD}\left(\mathrm{x} 10^{22}\right.$ ions $\left./ \mathrm{cm}^{3}\right)$ & 1.687 & 1.696 & 1.695 & 1.678 & 1.685 & 1.671 \\
\hline $\mathrm{N}\left(\mathrm{x} 10^{20}\right.$ ions $\left./ \mathrm{cm}^{3}\right)$ & 1.687 & 3.392 & 5.085 & 8.390 & 11.795 & 15.038 \\
\hline$r_{p}(\AA)$ & 7.292 & 5.777 & 5.048 & 4.272 & 3.813 & 3.516 \\
\hline $\mathrm{R}_{\mathrm{c}}\left(\mathrm{Eu}^{+3}-\mathrm{Eu}^{+3}\right)(\AA)$ & 14.364 & 11.380 & 9.943 & 8.415 & 7.511 & 6.927 \\
\hline $\mathrm{R}_{\mathrm{c}}\left(\mathrm{Gd}^{+3}-\mathrm{Eu}^{+3}\right)(\AA)$ & 4.622 & 4.614 & 4.615 & 4.631 & 4.624 & 4.637 \\
\hline
\end{tabular}




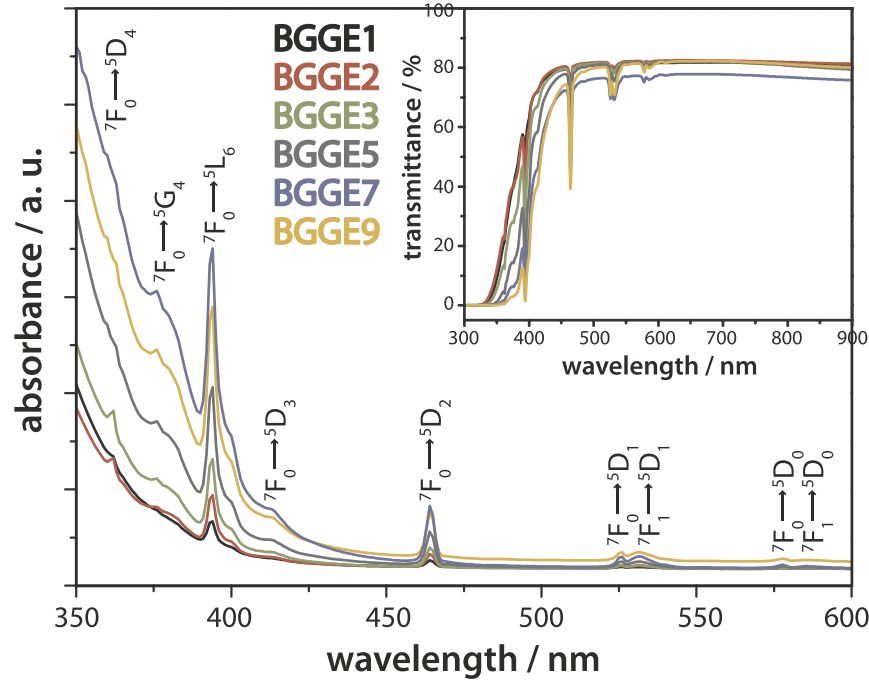

Fig. 3. Optical absorption spectra of BGGEx glasses over the spectral region of $350-600 \mathrm{~nm}$. The inset shows the transmission spectra in the spectral region of $300-900 \mathrm{~nm}$.

the presence of hydroxyl groups in the glass. The broad band observed at $1200-1600 \mathrm{~cm}^{-1}$ centered at around $1379 \mathrm{~cm}^{-1}$ is attributed to stretching vibrations of $\mathrm{BO}_{3}$ units with non-bridging oxygen (NBO). The strong absorption bands at 792 and $817 \mathrm{~cm}^{-1}$ are characteristic of bending and stretching vibrations of T-O-T $(\mathrm{T}=\mathrm{B}, \mathrm{Ge})$ linkages $[31,32]$.

\subsection{Absorption and transmittance spectra}

The absorption and transmittance spectra of $30 \mathrm{~B}_{2} \mathrm{O}_{3}-40 \mathrm{GeO}_{2}-(30$ $\mathrm{x}) \mathrm{Gd}_{2} \mathrm{O}_{3}-\mathrm{xEu}_{2} \mathrm{O}_{3}$ borogermanate glasses in the UV-vis regions are presented in Fig. 3. The absorption bands in the spectrum correspond to the $4 \mathrm{f}-4 \mathrm{f}$ optical transitions between the ground and the excited states of the $\mathrm{Eu}^{3+}$ ions [5].

The characteristic absorption peaks at 361, 376, 393, 413, 463, 525 and $577 \mathrm{~nm}$ are related to optical transitions from ${ }^{7} \mathrm{~F}_{0} \rightarrow{ }^{5} \mathrm{D}_{4},{ }^{5} \mathrm{G}_{4},{ }^{5} \mathrm{~L}_{6}$, ${ }^{5} \mathrm{D}_{3},{ }^{5} \mathrm{D}_{2},{ }^{5} \mathrm{D}_{1}$ and ${ }^{5} \mathrm{D}_{0}$, respectively. Optical transitions from ${ }^{7} \mathrm{~F}_{1}$ to ${ }^{5} \mathrm{D}_{1}$ and ${ }^{5} \mathrm{D}_{0}$ states of $\mathrm{Eu}^{3+}$ ions are associated with 531 and $588 \mathrm{~nm}$, respectively [33]. In this spectrum, ${ }^{7} \mathrm{~F}_{0} \rightarrow{ }^{5} \mathrm{~L}_{6}$ transition of the absorption peak at $393 \mathrm{~nm}$ is found to be more intense than other transitions. The ${ }^{7} \mathrm{~F}_{0} \rightarrow{ }^{5} \mathrm{D}_{4},{ }^{5} \mathrm{G}_{4},{ }^{5} \mathrm{D}_{3}$ transitions exhibit weak intensity, though ${ }^{7} \mathrm{~F}_{0} \rightarrow{ }^{5} \mathrm{D}_{3}$ transition is forbidden by the $\Delta \mathrm{J}$ selection rule. The transition of ${ }^{7} \mathrm{~F}_{0} \rightarrow{ }^{5} \mathrm{D}_{0}$ is spin-forbidden while the ${ }^{7} \mathrm{~F}_{0} \rightarrow{ }^{5} \mathrm{D}_{1}$ is magnetic dipole allowed. Notably, the intensity of peaks becomes more evident at higher $\mathrm{Eu}^{3+}$ ion content. The transitions below $352 \mathrm{~nm}$ cannot be seen in the transmittance spectra, because the cut-off edge of the glasses goes to higher wavelength and the absorption peaks $(273,301,311 \mathrm{~nm})$ of $\mathrm{Gd}^{3+}$ ion disappears. Remarkably all BGGEx glasses show a relatively flat transmittance coefficient within $78-82 \%$ range in the $440-900 \mathrm{~nm}$ wavelength regions. This is of significance in the higher light-yield output and high transparency for red emission of $\mathrm{Eu}^{3+}$ ions [34].

From absorption spectra (Fig.3) the optical band gap ( $E_{g}$ ) of BGGEx glasses can be calculated by using the well-known equation, as proposed by Tauc and Menth [35]:

$\alpha h v=B\left(h v-E_{g}\right)^{m}$

where ho is the incident photon energy, B is constant, $\mathrm{m}$ is a parameter which depends on the type of electronic transition responsible for absorption. $\mathrm{m}$ has values of $1 / 2$ and 2 , which correspond to direct and indirect allowed transitions, respectively. The absorption coefficient $\alpha$ can be defined as the ratio of absorbance and thickness. Therefore, by plotting $(\alpha h v)^{1 / m}$ vs. photon energy (Tauc's plot) the optical band gap can be determined from the extrapolation of the linear region of $(\alpha \mathrm{h} v)^{1 / \mathrm{m}}=0$. As shown in Table 2 , the calculated direct $\left(E_{g}^{d}\right)$ and
Table 2

The wavelength cut-off edge $\left(\lambda_{\text {cut-off }}\right)$ and optical band gap values for direct $\left(E_{g}^{d}\right)$ and indirect $\left(E_{g}^{i}\right)$ allowed transitions of $\mathrm{Eu}^{3+}$ doped borogermanate glasses.

\begin{tabular}{lrrrrrr}
\hline & BGGE1 & BGGE2 & BGGE3 & BGGE5 & BGGE7 & BGGE9 \\
\hline$\lambda_{\text {cut }- \text { off }}(\mathrm{nm})$ & 324.88 & 326.73 & 331.28 & 342.09 & 348.06 & 352.18 \\
$E_{g}^{d}(\mathrm{eV})$ & 3.66 & 3.64 & 3.60 & 3.48 & 3.38 & 3.28 \\
$E_{g}^{i}(\mathrm{eV})$ & 3.22 & 3.21 & 3.17 & 3.07 & 2.88 & 2.84 \\
\hline
\end{tabular}

indirect $\left(E_{g}^{i}\right)$ band gaps are in the range between $3.66-3.28$ and $3.22-2.84 \mathrm{eV}$, respectively. Band gap narrowing in BGGEx glasses is observed with the increase of $\mathrm{Eu}^{3+}$ doping concentration. This result can be attributed to the fact that the incorporation of more $\mathrm{Eu}^{3+}$ ions opens the glass network and generates more NBO [27]. This may also be an explanation for the shift of cut-off edge toward longer wavelengths with the increase $\mathrm{Eu}^{3+}$ content.

\subsection{Excitation and emission spectra}

Photoluminescence (PL) analysis provides valuable information about the optical properties of the sample. PL characterization has been performed in two parts: the emission and excitation spectrum. The excitation spectrum of $\mathrm{Eu}^{3+}$ doped borogermanate glasses were obtained by monitoring the ${ }^{5} \mathrm{D}_{0} \rightarrow{ }^{7} \mathrm{~F}_{2}$ transition of $\mathrm{Eu}^{3+}$ ions as shown in Fig. 4. The inset of Fig. 4 shows the $230-300 \mathrm{~nm}$ region of the spectrum where the excitation spectra is seen to compose of one broad band in $230-320 \mathrm{~nm}$ region and several sharp peaks in 310-600 nm region. Charge-transfer (CT) mechanism from the filled $2 \mathrm{p}$ shell of the $\mathrm{O}^{2-}$ ligand to the partially field $\mathrm{f}$ shell of $\mathrm{Eu}^{3+}$ ions is responsible for the formation of this broad band [36]. The characteristic excitation peaks of $\mathrm{Gd}^{3+}$ ions at $253 \mathrm{~nm}\left({ }^{8} \mathrm{~S}_{7 / 2} \rightarrow{ }^{6} \mathrm{D}_{9 / 2}\right), 273 \mathrm{~nm}\left({ }^{8} \mathrm{~S}_{7 / 22^{-}} \mathrm{I}_{11 / 2}\right), 298 \mathrm{~nm}$ $\left({ }^{8} \mathrm{~S}_{7 / 2^{-}}{ }^{6} \mathrm{P}_{5 / 2}\right)$ and $311 \mathrm{~nm}\left({ }^{8} \mathrm{~S}_{7 / 2^{-}}{ }^{6} \mathrm{P}_{7 / 2}\right)$ and $\mathrm{Eu}^{3+} 318 \mathrm{~nm}\left({ }^{7} \mathrm{~F}_{0^{-}}{ }^{5} \mathrm{H}_{\mathrm{J}}\right)$ are located on the broad CT band. This situation demonstrates the energy transfer from $\mathrm{Gd}^{3+}$ to $\mathrm{Eu}^{3+}$ ions in such a way that $\mathrm{Gd}^{3+}$ ions can absorb the energy at 273 and $311 \mathrm{~nm}$, and then transfer to $\mathrm{Eu}^{3+}$ ions [37]. The other sharp peaks lying at $362 \mathrm{~nm}\left({ }^{7} \mathrm{~F}_{0} \rightarrow{ }^{5} \mathrm{D}_{4}\right), 380 \mathrm{~nm}$ $\left({ }^{7} \mathrm{~F}_{0} \rightarrow{ }^{5} \mathrm{G}_{4}\right), 393 \mathrm{~nm}\left({ }^{7} \mathrm{~F}_{0} \rightarrow{ }^{5} \mathrm{~L}_{6}\right), 413 \mathrm{~nm}\left({ }^{7} \mathrm{~F}_{0} \rightarrow{ }^{5} \mathrm{D}_{3}\right), 463 \mathrm{~nm}\left({ }^{7} \mathrm{~F}_{0} \rightarrow{ }^{5} \mathrm{D}_{2}\right)$, $530 \mathrm{~nm}\left({ }^{7} \mathrm{~F}_{0} \rightarrow{ }^{5} \mathrm{D}_{1}\right)$ and $577 \mathrm{~nm}\left({ }^{7} \mathrm{~F}_{0} \rightarrow{ }^{5} \mathrm{D}_{0}\right)$ are related to the intra-4f forbidden transitions of $\mathrm{Eu}^{3+}$ ions between the ground and the excited states of $4 \mathrm{f}^{6}$ configuration $[20,33]$. The highest intensity in the

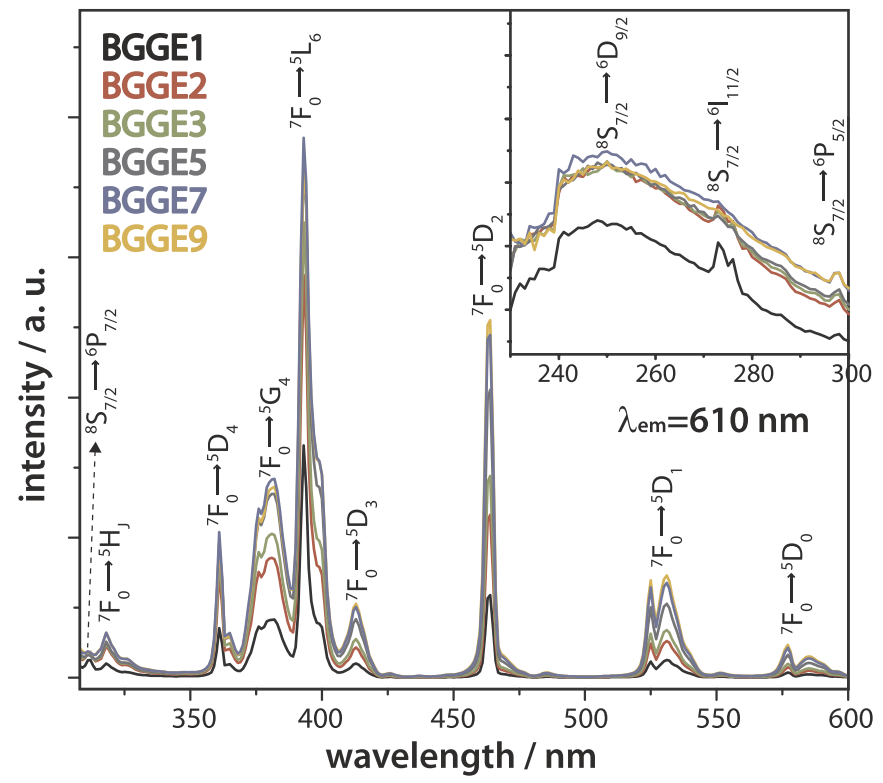

Fig. 4. Excitation spectra of BGGEx glasses. Inset shows the zoom of the excitation spectra in the spectral range of $230-300 \mathrm{~nm}$. 

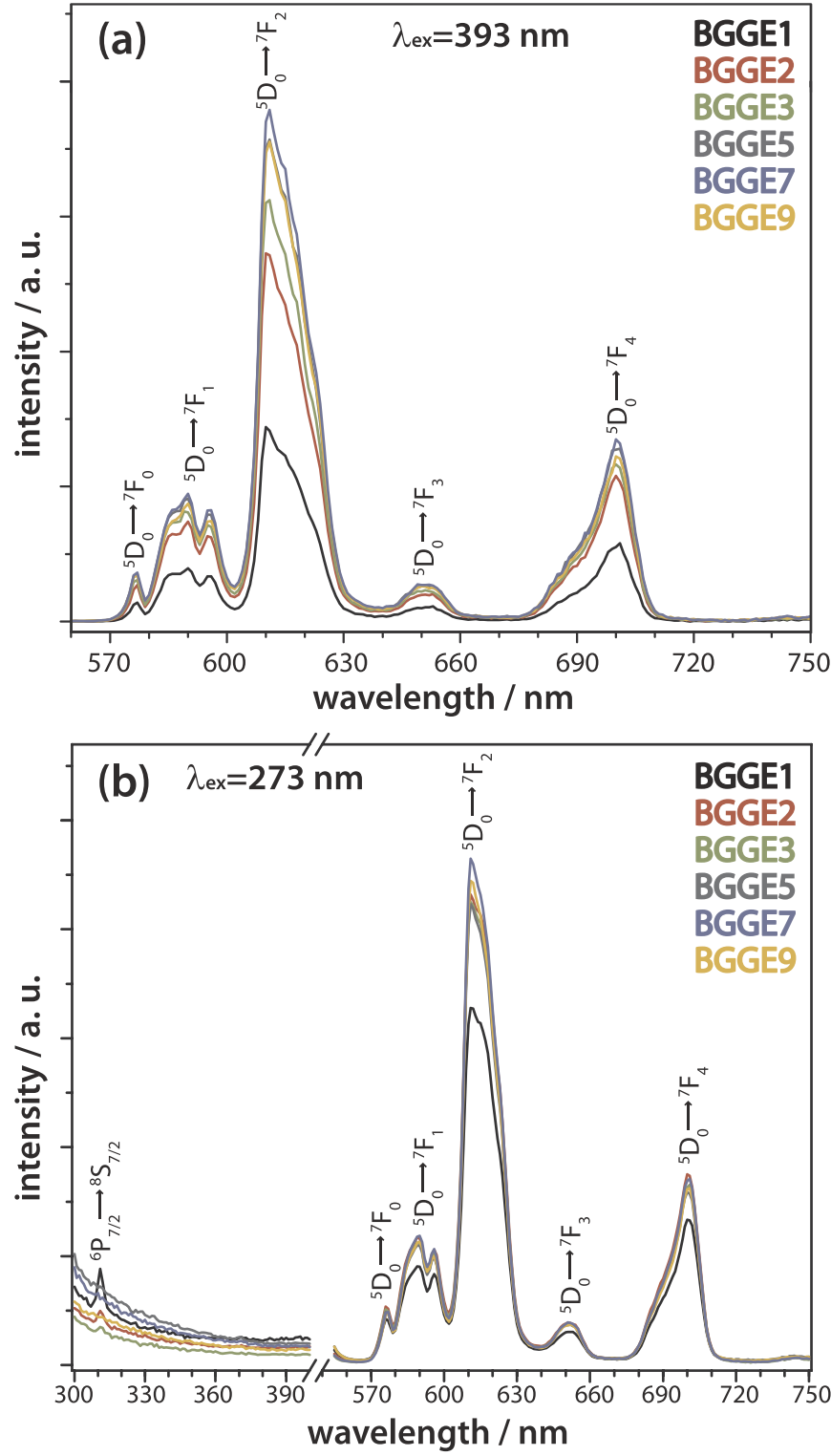

Fig. 5. Emission spectra of BGGEx glasses excited under 393 nm (a) and 273 nm (b).

excitation spectra of BGGEx glasses belongs to the transition at $393 \mathrm{~nm}$. Fig. 4 also illustrates that all excitation peaks become more intense up to $\mathrm{x}=7 \mathrm{~mol} \%$ and then weaken due to concentration quenching at $\mathrm{x}=9 \mathrm{~mol} \%$.

The emission spectra of BGGEx glasses have been measured by exciting at $393 \mathrm{~nm}$ in the wavelength range from 560 to $750 \mathrm{~nm}$ as shown in Fig. 5(a). The emission of $\mathrm{Eu}^{3+}$ arises from transitions between $4 \mathrm{f}-4 \mathrm{f}$ levels and is principally due to electric dipole or magnetic dipole interactions. The emission bands of $\mathrm{Eu}^{3+}$ ions can be assigned to ${ }^{5} \mathrm{D}_{0} \rightarrow{ }^{7} \mathrm{~F}_{0}$ $(575 \mathrm{~nm}),{ }^{5} \mathrm{D}_{0} \rightarrow{ }^{7} \mathrm{~F}_{1}(593 \mathrm{~nm}),{ }^{5} \mathrm{D}_{0} \rightarrow{ }^{7} \mathrm{~F}_{2}(610 \mathrm{~nm}),{ }^{5} \mathrm{D}_{0} \rightarrow{ }^{7} \mathrm{~F}_{3}(650 \mathrm{~nm})$, and ${ }^{5} \mathrm{D}_{0} \rightarrow{ }^{7} \mathrm{~F}_{4}(700 \mathrm{~nm})$ transitions [38]. It can be seen that the characteristic emission intensities of $\mathrm{Eu}^{3+}$ ions go up rapidly, reach the highest value for $\mathrm{x}=7 \mathrm{~mol} \%$ and then decrease due to concentration quenching. The strongest red emission, hypersensitive to the environment, is the electric dipole transition ${ }^{5} \mathrm{D}_{0} \rightarrow{ }^{7} \mathrm{~F}_{2}$ at $610 \mathrm{~nm}$ and follows the selection rule of $\Delta J=2$. Besides this, the ${ }^{5} \mathrm{D}_{0} \rightarrow{ }^{7} \mathrm{~F}_{1}(593 \mathrm{~nm})$ transition which is independent of local symmetry have magnetic dipole character and follows the selection rule of $\Delta J=1$ [39]. The ratio of integrated emission intensity of the ${ }^{5} \mathrm{D}_{0} \rightarrow{ }^{7} \mathrm{~F}_{2}$ transition to the ${ }^{5} \mathrm{D}_{0} \rightarrow{ }^{7} \mathrm{~F}_{1}$ transition is defined as red to orange ratio $(\mathrm{R} / \mathrm{O}$, also called as asymmetric ratio) obtained to estimate the local symmetry around the $\mathrm{Eu}^{3+}$
Table 3

Asymmetric ratio (R/O), J-O parameters $\left(\Omega_{2}\right.$ and $\left.\Omega_{4}\right)$, total radiative decay rate $\left(\mathrm{A}_{\text {rad }}\right)$, radiative decay time $\left(\tau_{\text {rad }}\right)$, and emission efficiency $(\eta)$ of BGGEx glasses.

\begin{tabular}{lrrrrrr}
\hline & BGGE1 & BGGE2 & BGGE3 & BGGE5 & BGGE7 & BGGE9 \\
\hline $\mathrm{R} / \mathrm{O}$ & 3.54 & 3.64 & 3.71 & 3.82 & 3.91 & 3.99 \\
$\Omega_{2}\left(\times 10^{-20} \mathrm{~cm}^{2}\right)$ & 5.54 & 5.69 & 5.84 & 6.04 & 6.18 & 6.30 \\
$\Omega_{4}\left(\times 10^{-20} \mathrm{~cm}^{2}\right)$ & 4.45 & 4.50 & 4.40 & 4.47 & 4.42 & 4.42 \\
$\mathrm{~A}_{\text {rad }}\left(\mathrm{s}^{-1}\right)$ & 4.63 & 4.81 & 4.73 & 4.75 & 4.89 & 4.85 \\
$\tau_{\text {rad }}(\mathrm{s})$ & 2.16 & 2.08 & 2.11 & 2.10 & 2.04 & 2.06 \\
$\eta(\%)$ & 71.6 & 75.3 & 72.2 & 70.6 & 71.1 & 66.7 \\
\hline
\end{tabular}

ions $[40,41]$. As can be seen from Table 3, R/O values increase linearly with the $\mathrm{Eu}^{3+}$ doping level indicating that the environment of $\mathrm{Eu}^{3+}$ ions are becoming more asymmetric.

Energy transfer from $\mathrm{Gd}^{3+}$ to $\mathrm{Eu}^{3+}$ ions were studied by obtaining the emission spectra of BGGEx glasses under $273 \mathrm{~nm}\left({ }^{8} \mathrm{~S}_{7 / 2}{ }^{6}{ }^{6} \mathrm{I}_{11 / 2}\right.$ for $\mathrm{Gd}^{3+}$ ion) excitation as illustrated in Fig. 5(b). The radiative transition of $\mathrm{Gd}^{3+}$ ion at $311 \mathrm{~nm}$ has maximum intensity and sharpness for $\mathrm{x}=1 \mathrm{~mol} \%$ [20]. In general, doping level has an effect on luminescent properties and energy transfer mechanism [42]. So it can be concluded that with the elevated concentration of $\mathrm{Eu}^{3+}$ ions the decrease in the emission intensity of $\mathrm{Gd}^{3+}$ at $311 \mathrm{~nm}$ and the increase in the characteristic emission intensities of $\mathrm{Eu}^{3+}$ ion may demonstrate energy transfer from $\mathrm{Gd}^{3+}$ to $\mathrm{Eu}^{3+}$. When the $\mathrm{Gd}^{3+}$ ions spend all of their energy by transferring it to the neighboring $\mathrm{Eu}^{3+}$ activators, concentration quenching of luminescence occurs [43].

The critical distances $\left(\mathrm{R}_{\mathrm{c}}\right)$ for $\mathrm{Gd}^{3+}-\mathrm{Eu}^{3+}$ and $\mathrm{Eu}^{3+}-\mathrm{Eu}^{3+}$ ion pairs for the optimum concentration were calculated to be 4.622 and $7.512 \AA$, respectively as given in Table 1 . The obtained distances are greater than $4 \AA$ indicating that the dominant mechanism of concentration quenching for BGGEx glasses is multipolar interaction [44]. Furthermore, it is found that the shorter related ion separations will quench $\mathrm{Gd}^{3+}\left(\mathrm{Eu}^{3+}\right)$ emission, as shown in Fig.5(b).

\subsection{Judd-Ofelt analysis}

The Judd-Ofelt analysis on the PL emission spectrum is used to gain knowledge about local structure and chemical bonding of rare-earth ions in host material $[45,46]$. The $\Omega_{\mathrm{J}}(\mathrm{J}=2,4$ and 6$) \mathrm{J}$-O parameters can be obtained from the ratio of the integrated emission intensities of corresponding transitions as follows:

$\Omega_{J}=\frac{\mathrm{S}\left[{ }^{5} \mathrm{D}_{0} \rightarrow{ }^{7} \mathrm{~F}_{\mathrm{J}}\right]}{\mathrm{S}\left[{ }^{5} \mathrm{D}_{0} \rightarrow{ }^{7} \mathrm{~F}_{1}\right]}\left(\frac{\nu\left[{ }^{5} \mathrm{D}_{0} \rightarrow{ }^{7} \mathrm{~F}_{1}\right]}{\nu\left[{ }^{5} \mathrm{D}_{0} \rightarrow{ }^{7} \mathrm{~F}_{\mathrm{J}}\right]}\right)^{3} \frac{\mathrm{S}_{\mathrm{md}}}{\mathrm{e}^{2}} \frac{9 \mathrm{n}^{2}}{\left(\mathrm{n}^{2}+2\right)^{2}}\left[\left\langle{ }^{5} \mathrm{D}_{0}\left|U^{(\lambda)}\right|{ }^{7} \mathrm{~F}_{\mathrm{J}}\right\rangle^{2}\right]{ }^{-1}$

$\mathrm{S}\left[{ }^{5} \mathrm{D}_{0} \rightarrow{ }^{7} \mathrm{~F}_{\mathrm{J}}\right]$ and $v\left[{ }^{5} \mathrm{D}_{0} \rightarrow{ }^{7} \mathrm{~F}_{\mathrm{J}}\right]$ are the integrated emission intensities and wavenumbers of the transitions from ${ }^{5} \mathrm{D}_{0}$ excited state to the low-lying ${ }^{7} \mathrm{~F}_{\mathrm{J}}$ states $(\mathrm{J}=0,1, \ldots, 6)$, respectively. e is the electric charge and $\left[9 n^{2} /\left(n^{2}+2\right)^{2}\right]$ is the Lorentz local field correction factor in terms of refraction index (n). The values of square reduced matrix elements, $\left\langle{ }^{5} \mathrm{D}_{0}\left|U^{(\lambda)}\right|{ }^{7} \mathrm{~F}_{\mathrm{J}}\right\rangle^{2}$, are not affected from the chemical environment of $\mathrm{Eu}^{3+}$ ion and are taken from Carnall et al. [33] (0.0032, 0.0023 and 0.0002 for $\lambda=2,4$ and 6 , respectively). $S_{\mathrm{md}}$, the magnetic dipole line strength value of ${ }^{5} \mathrm{D}_{0} \rightarrow{ }^{7} \mathrm{~F}_{1}$ transition, is also obtained from the literature [47]. The ${ }^{5} \mathrm{D}_{0} \rightarrow{ }^{7} \mathrm{~F}_{6}$ transition which lies in the near infrared region could not be observed in BGGEx glass due to the experimental limitations.

The total radiative decay rate, $A_{\text {rad }}$, can be expressed in terms of the radiative decay rates of each ${ }^{5} \mathrm{D}_{0}$ to ${ }^{7} \mathrm{~F}_{\mathrm{J}}(\mathrm{J}=0,1, \ldots, 6)$ transition

$A_{\text {rad }}=\sum_{J=0}^{6} A_{\text {rad }}\left[{ }^{5} \mathrm{D}_{0} \rightarrow{ }^{7} \mathrm{~F}_{\mathrm{J}}\right]$

As mentioned before, $\mathrm{J}=1$ and $\mathrm{J}=2,4$ transitions are conducted only by magnetic and electric dipole mechanisms, respectively, while the remaining ones $(\mathrm{J}=0,3,5)$ have both electric and magnetic 
contributions. Due to very low intensities, $J=0,3,5$ transitions can be neglected [48]. The radiative decay rate can be written as electric and magnetic dipole parts:

$A_{\text {rad }}\left[{ }^{5} \mathrm{D}_{0} \rightarrow{ }^{7} \mathrm{~F}_{\mathrm{J}}\right]=\frac{64 \pi^{4}}{3 h(2 J+1)}\left(\nu\left[{ }^{5} \mathrm{D}_{0} \rightarrow{ }^{7} \mathrm{~F}_{\mathrm{J}}\right]\right)^{3}\left[\frac{n\left(\mathrm{n}^{2}+2\right)^{2}}{9} S_{\text {ed }}+n^{3} S_{m d}\right]$

where $\mathrm{h}$ is Planck constant and $(2 \mathrm{~J}+1)$ is the degeneracy of the initial state. The electric dipole line strength $\left(\mathrm{S}_{\mathrm{ed}}\right)$ is given by

$S_{e d}=e^{2} \sum_{\lambda=2,4,6} \Omega_{\lambda}\left\langle{ }^{5} \mathrm{D}_{0}\left|U^{(\lambda)}\right|{ }^{7} \mathrm{~F}_{\mathrm{J}}\right\rangle^{2}$

The radiative decay time, $\tau_{\text {rad }}=1 / A_{\text {rad }}$, is the inverse of the total radiative decay rate. Using experimental decay time values $\left(\tau_{\exp }\right)$, the non-radiative decay time $\left(\tau_{\text {nrad }}\right)$ can be calculated from

$\frac{1}{\tau_{\text {nrad }}}=\frac{1}{\tau_{\exp }}-\frac{1}{\tau_{\text {rad }}}$

Finally, the emission efficiency $(\eta)$ is given by

$\eta=\frac{\tau_{\text {exp }}}{\tau_{\text {rad }}}$

The J-O parameters $\left(\Omega_{2}, \Omega_{4}\right)$, total radiative decay rates $\left(\mathrm{A}_{\text {rad }}\right)$, radiative $\left(\tau_{\text {rad }}\right)$ and non- radiative $\left(\tau_{\text {nrad }}\right)$ decay times and the emission efficiencies $(\eta)$ for $\mathrm{Eu}^{3+}$ doped borogermanate glasses have been calculated and tabulated in Table 3. In BGGEx glasses the $\Omega_{2}$ values increase with increasing $\mathrm{Eu}^{3+}$ content which indicates the Eu-O bond having more covalent character. Beside this $\Omega_{4}$ value does not affected by the change in $\mathrm{Eu}^{3+}$ concentration.

The same behaviors in $\mathrm{J}-\mathrm{O}$ parameters such as linear relation between $\Omega_{2}$ and doping level and secondly $\Omega_{2}>\Omega_{4}$ have also been observed for various other europium doped glasses such as borogermanate $[11,49]$, telluroborate [50] and tellurite [51]. This is the evidence of the covalent character of interaction between the $\mathrm{Eu}^{3+}$ ions and surrounding ligands.

\subsection{Luminescence decay curve}

Luminescence decay time measurements are very convenient for determining the energy transfer mechanism and luminescence quenching behavior. Fig. 6(a) presents the decay time measurements of $\mathrm{Gd}^{3+}{ }^{6} \mathrm{P}_{7 / 2} \rightarrow{ }^{8} \mathrm{~S}_{7 / 2}$ transition (311 nm) excited at $273 \mathrm{~nm}$ in BGGEx glasses. As can be seen from the figure that the curve does not show exponential behavior therefore decay time was taken as corresponding time at where luminescence intensity has $\mathrm{e}^{-1}$ of its initial value. The decreasing decay time of $\mathrm{Gd}^{3+}{ }^{6} \mathrm{P}_{7 / 2} \rightarrow{ }^{8} \mathrm{~S}_{7 / 2}$ transition with increasing $\mathrm{Eu}^{3+}$ ion concentration is proof of higher energy transfer from $\mathrm{Gd}^{3+}$ to $\mathrm{Eu}^{3+}$ ions.

The effect of $\mathrm{Eu}^{3+}$ concentration on decay times of ${ }^{5} \mathrm{D}_{0}-{ }^{7} \mathrm{~F}_{2}$ $(610 \mathrm{~nm})$ transition under $273 \mathrm{~nm}$ excitation is shown in Fig. 6(b). The luminescence decay time curves of BGGEx glasses well fitted with twoexponential components.

Upon the increase in $x$ values, the decay times reduce and after concentration quenching at $\mathrm{x}=7 \mathrm{~mol} \%$ its decrease becomes more rapid. Variations in luminescence decay time occur due to self-generated quenching that happen between $\mathrm{Eu}^{3+}$ ions in the host [52].

\section{Conclusion}

Borogermanate glasses in the $\mathrm{B}_{2} \mathrm{O}_{3}-\mathrm{GeO}_{2}-\mathrm{Gd}_{2} \mathrm{O}_{3}$ ternary system have been prepared by melt quenching method and their physical, optical and luminescent properties were investigated as a function of $\mathrm{Eu}^{3+}$ ion concentration. These glasses measured densities up to $4.824 \mathrm{~g} / \mathrm{cm}^{3}$ are due to the presence of heavy $\mathrm{Gd}^{3+}$ element in the glass network. The glasses exhibited a high transparency of about $80 \%$ in the 440 to $900 \mathrm{~nm}$ region. It was also found that the optical band gaps evaluated from the absorption spectra can be narrowed by increasing
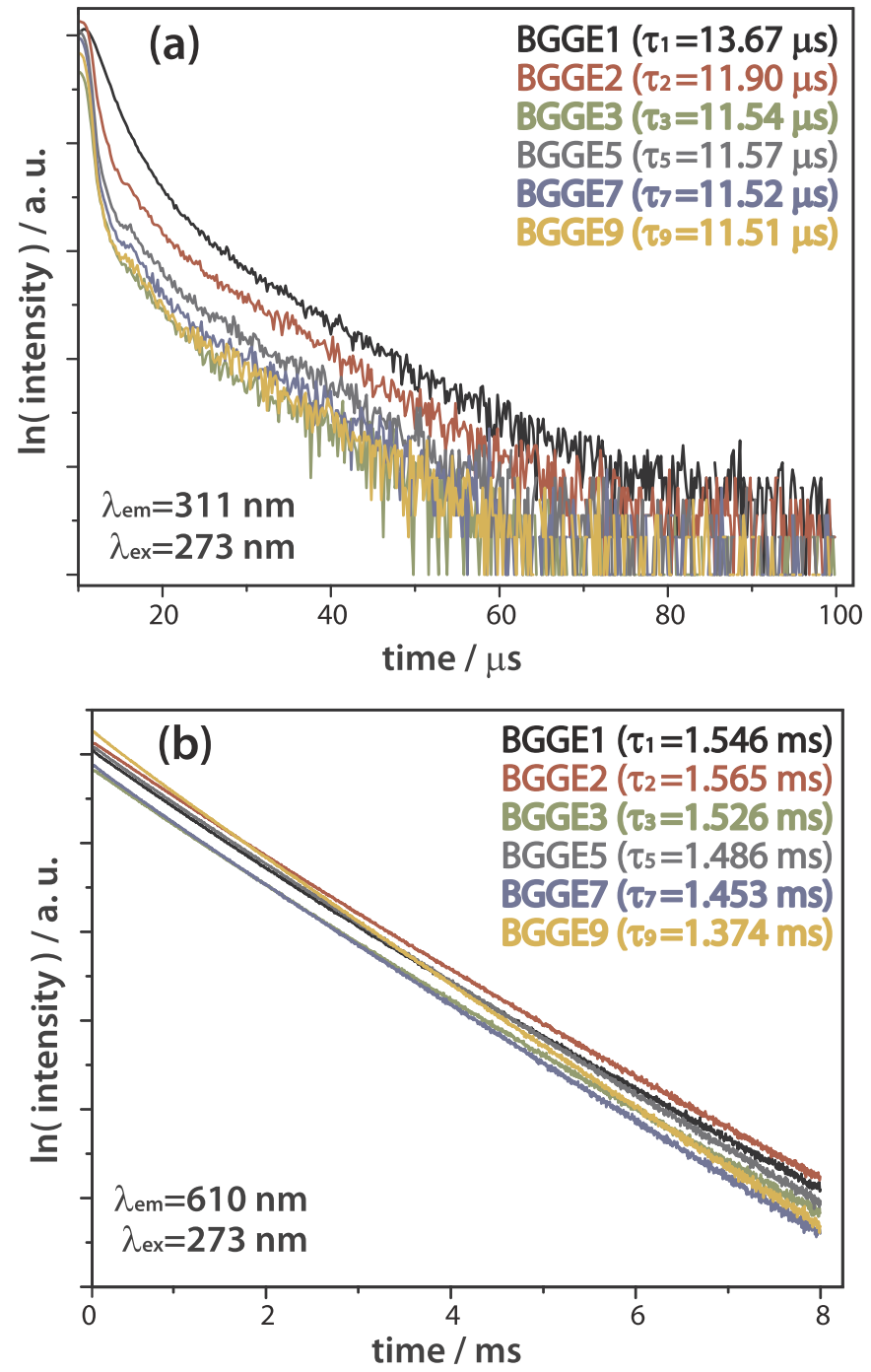

Fig. 6. Luminescence decay time curves of (a) $\mathrm{Gd}^{3+}$ (monitoring the PL peak of $\mathrm{Gd}^{3+}$ at $311 \mathrm{~nm}$ ) and (b) $\mathrm{Eu}^{3+}$ (monitoring the PL peak of $\mathrm{Eu}^{3+}$ at $610 \mathrm{~nm}$ ) in BGGEx glasses under $273 \mathrm{~nm}$ excitation, respectively.

content of $\mathrm{Eu}^{3+}$. This effect was found to have a correlation with the changes in the glass structure where the addition of $\mathrm{Eu}^{3+}$ to the glass network is known to create non-bridging oxygen. The energy transfer process from $\mathrm{Gd}^{3+}$ to $\mathrm{Eu}^{3+}$ ions in $\mathrm{Eu}^{3+}$ doped borogermanate glasses has been identified based on emission and excitation spectra and luminescence decay curves. The energy transfer efficiency from $\mathrm{Gd}^{3+}$ to $\mathrm{Eu}^{3+}$ reached $75 \%$ when the content of $\mathrm{Eu}^{3+}$ was greater than $1 \mathrm{~mol} \%$. Judd-Ofelt parameters were evaluated from the emission spectrum. For all BGGEx glasses, J-O parameter $\Omega_{2}$ have been found to be greater than $\Omega_{4}$, which provides evidence of the covalent character of interaction between the $\mathrm{Eu}^{3+}$ ions and surrounding ligands. Moreover, this correlation between the increment of $\Omega_{2}$ and concentration of $\mathrm{Eu}^{3+}$ ions suggests increased Eu-O covalency and more distortion of the local symmetry. The results obtained from this study are thought to be of value in furthering studies on $\mathrm{Eu}^{3+}$ doped borogermanate glasses and imply that the these glasses are of significance for scintillating applications.

\section{Acknowledgments}

We wish to express our gratitude to the financial support provided by The Scientific and Technological Research Council of Turkey (TÜBITAK, Project number: 114M477). 


\section{References}

[1] E. Álvarez, M.E. Zayas, J.A. Rivera, F.F. Domínguez, R.P.D. Zamorano, U. Caldiño, New reddish-orange and greenish-yellow light emitting phosphors: $\mathrm{Eu}^{3+}$ and $\mathrm{Tb}^{3+}$ / $\mathrm{Eu}^{3+}$ in sodium germanate glass, J. Lumin. 153 (2014) 198-202.

[2] I. Iparraguirre, J. Azkargorta, J.M. Fernandez-Navarro, M. Al-Saleh, J. Fernandez, R. Balda, Laser action and upconversion of $\mathrm{Nd}^{3+}$ in tellurite bulk glass, J. NonCryst. Solids 353 (2007) 990.

[3] S. Tanabe, Rare-earth-doped glasses for fiber amplifiers in broadband telecommunication, C. R. Chimie 5 (2002) 815-824.

[4] G.S. Maciel, C.B.D. Arau, Y. Messaddeq, M.A. Aegerter, Frequency upconversion in $\mathrm{Er}^{3+}$ doped fluoroindate glasses pumped at $1.48 \mathrm{~mm}$, Phys Rev B 55 (10) (1997) 6335-6342.

[5] K. Marimuthu, R.T. Karunakaran, S.S. Babu, G. Muralidharan, S. Arumugam, C.K. Jayasankar, Structural and spectroscopic investigations on $\mathrm{Eu}^{3+}$ doped alkali fluoroborate glasses, Solid State Sci 11 (2009) 1297-1302.

[6] S.A. Dalhatu, R. Hussin, K. Deraman, Structural and luminescence properties of $\mathrm{Eu}^{3+}$ doped magnesium sulfide borate glass and crystal, Chin. J. Phys. 54 (2016) 877-882.

[7] U. Caldiño, G. Muñoz, H.I. Camarillo, A. Speghini, M. Bettinelli, Down-shifting by energy transfer in $\mathrm{Tb}^{3+} / \mathrm{Dy}^{3+}$ codoped zinc phosphate glasses, J. Lumin. 161 (2015) 142-146.

[8] Z. Wu, B. Chen, X. Li, J. Zhang, J. Sun, H. Zhong, H. Zheng, L. Tong, H. Xia, Optical transition properties, energy transfer mechanism and luminescent thermal stability of $\mathrm{Sm}^{3+}$ doped silicate glasses, J. Alloy Compd. 663 (2016) 545-551.

[9] C. Zuo, A. Xiao, Z. Zhou, Y. Chen, X. Zhang, X. Ding, X. Wang, Q. Ge, Spectroscopic properties of $\mathrm{Ce}^{3+}$ doped $\mathrm{BaO}-\mathrm{Gd}_{2} \mathrm{O}_{3}-\mathrm{Al}_{2} \mathrm{O}_{3}-\mathrm{B}_{2} \mathrm{O}_{3}-\mathrm{SiO}_{2}$ glasses, J. Non-Cryst. Solids 452 (2016) 35-39.

[10] X.Y. Sun, D.G. Jiang, S.W. Chen, G.T. Zheng, S.M. Huang, M. Gu, Z.J. Zhang, J.T. Zhao, $\mathrm{Eu}^{3+}$ activated borogermanate scintillating glass with a high $\mathrm{Gd}_{2} \mathrm{O}_{3}$ content, J. Am. Ceram. Soc. 96 (5) (2013) 1483-1489.

[11] X. Liu, Y. Qiao, G. Dong, S. Ye, B. Zhu, G. Lakshminarayana, D. Chen, J. Qiu, Cooperative downconversion in $\mathrm{Yb}^{3+}-\mathrm{RE}^{3+}(\mathrm{RE}=\mathrm{Tm}$ or $\mathrm{Pr})$ codoped lanthanum borogermanate glasses, Opt. Lett. 33 (23) (2008) 2858-2860.

[12] G.E. Malashkevich, V.N. Sigaev, N.V. Golubev, V.I. Savinkov, P.D. Sarkisov, I.A. Khodasevich, V.I. Dashkevich, A.V. Mudryi, Luminescence of borogermanate glasses activated by $\mathrm{Er}^{3+}$ and $\mathrm{Yb}^{3+}$ ions, J. Non-Cryst. Solids 357 (2011) 67-72.

[13] Z. Na, K.N. Sharafudeen, D. Guoping, P. Mingying, Q. Jianrong, Mixed network effect of broadband near-infrared emission in bi-doped $\mathrm{B}_{2} \mathrm{O}_{3}-\mathrm{GeO}_{2}$ glasses, J. Am. Ceram. Soc. 95 (12) (2012) 3842-3846.

[14] J. Rajagukguk, J. Kaewkhao, M. Djamal, R. Hidayat, Suprijadi, Y. Ruangtaweep, Structural and optical characteristics of $\mathrm{Eu}^{3+}$ ions in sodium-leadzinc-lithium-borate glass system, J. Mol. Struct. 1121 (2016) 180-187.

[15] X.Y. Sun, D.G. Jiang, W.F. Wang, C.Y. Cao, Y.N. Li, G.T. Zhen, H. Wang, X.X. Yang, H.H. Chen, Z.J. Zhang, J.T. Zhao, Luminescence properties of $\mathrm{B}_{2} \mathrm{O}_{3}-\mathrm{GeO}_{2}-\mathrm{Gd}_{2} \mathrm{O}_{3}$ scintillating glass doped with rare-earth and transition-metal ions, Nucl. Instrum. Meth. A 716 (2013) 90-95.

[16] X.Y. Sun, W.F. Wang, X.G. Yu, Y.N. Li, X.X. Yang, H.H. Chen, Z.J. Zhang, J.T. Zhao, Luminescent properties of $\mathrm{Eu}^{3+}$ activated $(70-\mathrm{x}) \mathrm{B}_{2} \mathrm{O}_{3}-\mathrm{xGeO}_{2}-\mathrm{Gd}_{2} \mathrm{O}_{3}$ scintillating glasses, IEEE Trans. Nucl. Sci. 61 (1) (2014) 380-384.

[17] X.Y. Sun, D.G. Jiang, Y.Z. Suna, X. Zhang, Q.L. Hu, Y. Huang, Y. Tao, Eu ${ }^{3+}$ activated $\mathrm{B}_{2} \mathrm{O}_{3}-\mathrm{GeO}_{2}-\mathrm{RE}_{2} \mathrm{O}_{3}\left(\mathrm{RE}=\mathrm{Y}^{3+}, \mathrm{La}^{3+}\right.$ and $\left.\mathrm{Gd}^{3+}\right)$ borogermanate scintillating glasses, J. Non-Cryst. Solids 389 (2014) 72-77.

[18] Y. Gandhi, P. Rajanikanth, M.S. Rao, V.R. Kumar, N. Veeraiah, M. Piasecki, Effect of tin ions on enhancing the intensity of narrow luminescence line at $311 \mathrm{~nm}$ of $\mathrm{Gd}^{3+}$ ions in $\mathrm{Li}_{2} \mathrm{O}-\mathrm{PbO}-\mathrm{P}_{2} \mathrm{O}_{5}$ glass system, Opt. Mater. 57 (2016) 39-44.

[19] W. Chewpraditkul, X. He, D. Chen, Y. Shen, Q. Sheng, B. Yu, M. Nikl, R. Kucerkova, A. Beitlerova, C. Wanarak, A. Phunpueok, Luminescence and scintillation of $\mathrm{Ce}^{3+}$ doped oxide glass with high $\mathrm{Gd}_{2} \mathrm{O}_{3}$ concentration, Phys. Status Solidi 208 (12) (2011) 2830-2832.

[20] D. He, C. Yu, J. Cheng, S. LI, L. Hu, Energy transfer between $\mathrm{Gd}^{3+}$ and $\mathrm{Tb}^{3+}$ in phosphate glass, J. Rare Earth. 29 (1) (2011) 48-51.

[21] Y. Zhang, J. Lv, N. Ding, S. Jiang, T. Zheng, J. Li, Tunable luminescence and energy transfer from $\mathrm{Gd}^{3+}$ to $\mathrm{Tb}^{3+}$ ions in silicate oxyfluoride scintillating glasses via varying $\mathrm{Tb}^{3+}$ concentration, J. Non-Cryst. Solids 423-424 (2015) 30-34.

[22] C.R. Kesavulu, H.J. Kim, S.W. Lee, J. Kaewkhao, E. Kaewnuam, N. Wantana, Luminescence properties and energy transfer from $\mathrm{Gd}^{3+}$ to $\mathrm{Tb}^{3+}$ ions in gadolinium calcium silicoborate glasses for green laser application, J. Alloy Compd. 704 (2017) 557-564.

[23] N. Wantana, S. Kaewjaeng, S. Kothan, H.J. Kim, J. Kaewkhao, Energy transfer from $\mathrm{Gd}^{3+}$ to $\mathrm{Sm}^{3+}$ and luminescence characteristics of $\mathrm{CaO}-\mathrm{Gd}_{2} \mathrm{O}_{3}-\mathrm{SiO}_{2}-\mathrm{B}_{2} \mathrm{O}_{3}$ scintillating glasses, J. Lumin. 181 (2017) 382-386.

[24] J. Kaewkhao, N. Wantana, S. Kaewjaeng, S. Kothan, H.J. Kim, Luminescence characteristics of $\mathrm{Dy}^{3+}$ doped $\mathrm{Gd}_{2} \mathrm{O}_{3}-\mathrm{CaO}-\mathrm{SiO}_{2}-\mathrm{B}_{2} \mathrm{O}_{3}$ scintillating glasses, J. Rare Earth 34 (6) (2016) 583-589.

[25] F. Zaman, G. Rooh, N. Srisittipokakun, H.J. Kim, E. Kaewnuam, P. Meejitpaisan, J. Kaewkhao, Scintillation and luminescence characteristics of $\mathrm{Ce}^{3+}$ doped in $\mathrm{Li}_{2} \mathrm{O}-\mathrm{Gd}_{2} \mathrm{O}_{3}-\mathrm{BaO}-\mathrm{B}_{2} \mathrm{O}_{3}$ scintillating glasses, Radiat. Phys. Chem. 130 (2017) $158-163$.

[26] J. Fu, M. Kobayashi, S. Sugimoto, J.M. Parker, $\mathrm{Eu}^{3+}$ activated heavy scintillating glasses, Mater. Res. Bull. 43 (2008) 1502-1508.

[27] X.Y. Liu, H. Guo, S.X. Da1, M.Y. Peng, Q.Y. Zhang, Energy transfer and thermal stability in $\mathrm{Bi}^{3+} / \mathrm{Eu}^{3+}$ co-doped germanium-borate glasses for organic-resin-free UV LEDs, Opt. Mater. Express 6 (11) (2016) 3574-3585.

[28] J.S. McCloy, Methods for prediction of refractive index in glasses for the infrared, SPIE Proc. 8016 (2011) 1-16.

[29] A. Hoaksey, J. Woods, K.N.R. Taylor, Luminescence of $\mathrm{Tb}^{3+}$ ions in silicate glasses, J. Lumin. 17 (1978) 385-400.

[30] B. Bhatia, S.L. Meena, V. Parihar, M. Poonia, Optical basicity and polarizability of $\mathrm{Nd}^{3+}$-doped bismuth borate glasses, N. J. Glass Ceram. 5 (2015) 44-52.

[31] N. Zhang, K.N. Sharafudeen, G. Dong, M. Peng, J. Qiu, Mixed network effect of broadband near-infrared emission in Bi-Doped glasses, J. Am. Ceram. Soc. 95 (12) (2012) 3842-3846.

[32] N. Zhang, J. Qiu, G. Dong, Z. Yang, O. Zhang, M. Peng, Broadband tunable nearinfrared emission of Bi-doped composite germanosilicate glasses, J. Mater. Chem. 22 (7) (2012) 3154-3159.

[33] W.T. Carnall, P.R. Fields, K. Rajnak, Electronic energy levels of the trivalent lanthanide aquo ions. IV. $\mathrm{Eu}^{3+}$, J. Chem. Phys. 49 (1968) 4450-4455.

[34] X.Y. Sun, Z.P. Ye, Z.J. Zhang, L.W. Liu, D.P. Chen, J.T. Zhao, Energy transfer study on dense $\mathrm{Eu}^{3+} / \mathrm{Tb}^{3+}$ coactivated oxyfluoride borogermanate scintillating glasses, $\mathrm{J}$. Am. Ceram. Soc. 98 (3) (2015) 781-787.

[35] J. Tauc, A. Menth, States in the gap, J. Non-Cryst. Solids 8-10 (1972) 569-584.

[36] J.C. Krupa, I. Gerard, A. Mavolet, Electronic structure of f-element systems in the Uv and Vuv energy range, Acta Phys. Pol. A 84 (1993) 843-848.

[37] K.W. Meert, V.A. Morozov, A.M. Abakumov, J. Hadermann, D. Poelman, P.F. Smet, Energy transfer in $\mathrm{Eu}^{3+}$ doped scheelites: use as thermographic phosphor, Opt. Express 22 (2014) A961-A972.

[38] W.T. Carnall, P.R. Fields, K. Rajnak, Spectral intensities of the trivalent lanthanides and actinides in solution. II. $\mathrm{Pm}^{3+}, \mathrm{Sm}^{3+}, \mathrm{Eu}^{3+}, \mathrm{Gd}^{3+}, \mathrm{Tb}^{3+}, \mathrm{Dy}^{3+}$, and $\mathrm{Ho}^{3+}, \mathrm{J}$. Chem. Phys. 49 (1968) 4412-4423.

[39] H. Yang, J. Shi, M. Gong, H. Liang, A novel red phosphor: $\mathrm{Ca}_{2} \mathrm{GeO}_{4}: \mathrm{Eu}^{3+}$, J. Rare Earth 28 (4) (2010) 519-522.

[40] L. Zur, Structural and luminescence properties of $\mathrm{Eu}^{3+}, \mathrm{Dy}^{3+}$ and $\mathrm{Tb}^{3+}$ ions in lead germanate glasses obtained by conventional high-temperature melt-quenching technique, J. Mol. Struct. 1041 (2013) 50-54.

[41] J. Kaewkhaoa, K. Boonin, P. Yasaka, H.J. Kim, Optical and luminescence characteristics of $\mathrm{Eu}^{3+}$ doped zinc bismuth borate (ZBB) glasses for red emitting device, Mater. Res. Bull. 71 (2015) 37-41.

[42] N. Liu, J.Y. Si, G.M. Cai, Y. Tao, Crystal structure, luminescent properties and energy transfer of $\mathrm{Eu}^{3+} / \mathrm{Dy}^{3+}$ doped $\mathrm{GdNbTiO}_{6}$ broad band excited phosphors, RSC Adv. 6 (2016) 50797-50807.

[43] G. Blasse, Energy transfer in oxidic phosphors, Philips Res. Rep. 28 (6) (1968) 444-445.

[44] F. Yang, Y. Liang, M. Liu, X. Li, M. Zhang, N. Wang, Photoluminescence properties of novel red-emitting NaSrBO3:Eu ${ }^{3+}$ phosphor for near-UV light-emitting diodes, Opti. Laser Technol 46 (2013), pp. 14-19.

[45] B.R. Judd, Optical absorption intensities of rare-earth ions, Phys. Rev. 127 (1962) $750-761$.

[46] G.S. Ofelt, Intensities of crystal spectra of rare earth ions, J. Chem. Phys. 37 (1962) $511-520$.

[47] M.J. Weber, T.E. Varitimo, B.H. Matsinge, Optical intensities of rare-earth ions in yttrium orthoaluminate, Phys. Rev. B 8 (1973) 47.

[48] N.B.D. Lima, J.D.L. Dutra, S.M.C. Gonçalves, R.O. Freire, A.M. Simas, Chemical partition of the radiative decay rate of luminescence of Europium complexes, Sci. Rep. 6 (2016) 21204-21216.

[49] X.Y. Sun, X. Zhang, H.H. Chen, Q.L. Hu, W.F. Wang, Z.J. Zhang, J.T. Zhao, Investigation on the luminescent properties of $\mathrm{Eu}^{3+}$ activated dense oxyfluoride borogermanate scintillating glasses, J. Non-Cryst. Solids 404 (2014) 162-166.

[50] K. Annapoorani, K. Marimuthu, Spectroscopic properties of $\mathrm{Eu}^{3+}$ ions doped Barium telluroborate glasses for red laser applications, J. Non-Cryst. Solids 463 (2017) 148-157.

[51] W. Stambouli, H. Elhouichet, B. Gelloz, M. Ferid, Optical and spectroscopic properties of Eu-doped tellurite glasses and glass ceramics, J. Lumin. 138 (2013) 201-208.

[52] K.K. Rasu, D. Balaji, S.M. Babu, Spectroscopic properties of $\mathrm{Eu}^{3+}: \mathrm{KLa}\left(\mathrm{WO}_{4}\right)_{2}$ novel red phosphors, J. Lumin. 170 (2016) 547-555. 